\title{
ESTUDO DE CIRCUITOS ELÉTRICOS POR MEIO DE DESENHOS DOS ALUNOS: UMA ESTRATÉGIA PEDAGÓGICA PARA EXPLICITAR AS DIFICUL- DADES CONCEITUAIS ${ }^{+*}$
}

\author{
Carlos Eduardo Laburú \\ Departamento de Física - Universidade Estadual de Londrina \\ Londrina - PR \\ Amândio Augusto Gouveia ${ }^{2}$ \\ Mestrado em Ensino de ciências e Educação Matemática - UEL \\ Marcelo Alves Barros ${ }^{2}$ \\ Instituto de Física de São Carlos - USP \\ São Carlos - SP
}

\section{Resumo}

Este artigo propõe incorporar a linguagem de desenhos ao tradicional tratamento da simbologia convencional quando do estudo de circuitos elétricos. A proposta objetiva trabalhar esse modo de representação com alunos de Ensino Médio em paralelo com a linguagem científica. Mostramos que o modo pictórico, que não exige o conhecimento dos códigos oficiais, tem uma potencialidade de detectar dificuldades conceituais dos alunos, evitando que estas sejam encobertas pela abstrata e antiintuitiva representação oficial. A ideia é permitir que os aprendizes, durante o processo de ensino, expressem-se por meio de símbolos diretos e intuitivos, ao invés de estarem obrigados a usar exclusivamente as normas e

\footnotetext{
+ Electric circuits study through students' drawings: a pedagogic strategy to make explicit the conceptual difficulties

* Recebido: abril de 2008. Aceito: outubro de 2008.

${ }^{1}$ Apoio CNPq, Fundação Araucária, Faepe/UEL.

2 Apoio CNPq.
} 
códigos da simbologia oficial, como habitualmente é feito. Veremos que a modalidade instrucional baseada nos desenhos dos alunos permite ao professor uma oportunidade de gerar discussões e ir acompanhando a construção do conhecimento de seus estudantes em sala de aula.

Palavras-chave: Representação por desenho; dificuldades conceituais; circuito elétrico; Ensino Médio.

\begin{abstract}
This article proposes to incorporate the language of the drawings to the traditional conventional symbolism used in the study of electrical circuits. The objective is to work this representation mode with High School students together with the scientific language. We show that the pictorial mode, that doesn't demand the knowledge of the official codes, has the potential to detect students' conceptual difficulties, preventing them from being hidden by the abstract and anti-intuitive official symbolism. The idea is to permit that learners, during the learning process, may express themselves through direct and intuitive symbols, instead of being forced to use exclusively the norms and codes from official semiotics, as it has been traditionally done. We will see that the instructional modality based on the students' drawings allows a rich opportunity for the teacher to generate discussions and to keep up with the construction of his/her student' knowledge in classroom.
\end{abstract}

Keywords: Representation by drawing; conceptual difficulties; electric circuit; High School.

\title{
I. Introdução
}

A dificuldade dos alunos em ler imagens e dar-lhes interpretação coerente e compatível com a significação para as quais foram propostas vem sendo objeto de recentes trabalhos na educação científica (COLIN; VIENNOT, 2002; STYLIANIDOU et al., 2002). As imagens não podem ser consideradas trivialmente inteligíveis e transparentes para os estudantes. Para uma leitura correta de um 
documento contendo imagens é preciso um conhecimento de fundo capaz de entrar em ressonância com a mensagem que a imagem pretende transmitir (PINTÓ; AMETLLER 2002, p. 333 e 335).

Diferentemente das pesquisas anteriores, que estudam a imagem num sentido abrangente, este trabalho pretende concentrar a atenção num tipo específico de imagem. Interessa-nos estudar as imagens baseadas em esquemas simbólicos, que não têm semelhança direta e imediata com o que está reproduzido, sendo indispensável um conhecimento de suas regras, seus códigos e significados para compreendê-las. Muito utilizados em certos conteúdos de Física, os esquemas simbólicos baseiam-se num conjunto de convenções prévias; são deveras abstratos e pretendem figurar o real de maneira geométrica. Apesar da pesquisa de Colin \& Viennot (2002) conter algumas imagens com essas características, a análise aí realizada, como a das outras duas pesquisas citadas, procura investigar padrões de leitura que o desenhista pretendeu fornecer e que podem induzir a uma má interpretação do que querem figurar ou deixam de auxiliar o texto que desejam ilustrar.

Como esclareceremos à frente, partimos do pressuposto de que aprender conhecimentos que dispõem e se utilizam de esquemas simbólicos apresenta uma maior dificuldade para grande parte dos alunos. Uma justificativa para isso se encontra nas adicionais abstração e memorização necessárias envolvidas com os símbolos desses conhecimentos, que outros estudos dispensam e que apenas utilizam a linguagem natural. Os símbolos e os esquemas que os articulam formam uma linguagem de códigos, regras e significados próprios que precisa ser aprendida para que os conceitos físicos associados sejam elaborados. Ainda mais importante, quando acontece um mau domínio dessa linguagem, os símbolos e esquemas correspondentes podem encobrir obstáculos conceituais que são fundamentais para o entendimento do conteúdo estudado. Daí fica a pergunta: qual o sentido de se exigir dos alunos, no início da instrução, as representações oficiais, quando se sabe que por detrás das mesmas apresenta-se um conjunto de problemas conceituais? Trabalhar com códigos oficiais deveria ser uma etapa final de um processo de ensino e não o começo.

No ensino de Física no Ensino Médio, o conteúdo de circuitos elétricos é abundante de simbologias que fogem do senso comum e tornam a aprendizagem problemática para os alunos. Tendo isso em consideração, propomos utilizar a representação por desenhos, realizada pelos próprios alunos, que prescinde dos códigos oficiais, como uma orientação instrucional que potencialize a detecção de dificuldades conceituais de aprendizagem, nesse conteúdo. Tal proposta tem aproximações com a investigação de Pacca et al. (2003). Todavia, esses autores objeti- 
varam usar a linguagem do desenho para entender as concepções dos alunos sobre corrente elétrica, considerando-a do ponto de vista da estrutura da matéria e da geração dessa corrente. No caso, os sujeitos pesquisados ainda não haviam estudado o assunto ou estavam iniciando. Diferentemente de Pacca et al., utilizamos o desenho como um instrumento pedagógico para identificar dificuldades de aprendizagem durante uma etapa do ensino de circuitos elétricos. Outra distinção está na abordagem dada ao conteúdo. Nela, os conceitos envolvidos, como de corrente elétrica, particularmente, foram tratados de forma tradicional, sendo que uma visão mais operacional, baseada nas leis de Kirchhoff, etc., foi predominante, como acostuma acontecer nessa etapa do ensino desse conteúdo, quando comparada ao detalhamento microscópico dado pelos autores mencionados.

Este trabalho pretende mostrar que a incorporação da linguagem de desenhos à linguagem simbólica oficial favorece a manifestação e o acompanhamento das ideias dos alunos a respeito do que está sendo ensinado. Constataremos que o modo pictórico favorece detectar dificuldades conceituais, evitando que estas sejam encobertas pela abstrata e não intuitiva simbologia convencional. A ideia, portanto, é abrir um espaço de discussão, a fim de permitir que os aprendizes, durante o processo de ensino de circuitos elétricos, expressem-se por meio de sua própria representação, em vez de estarem obrigados a usar, de forma exclusiva, as normas e os códigos de uma semiótica oficial, como se faz tradicionalmente.

\section{Fundamentação teórica}

Nas últimas três décadas do século vinte, o desenvolvimento das pesquisas na área de educação científica teve como um dos seus importantes resultados a elaboração de um programa de pesquisa conhecido pelo nome de modelo de mudança conceitual. Esse modelo passou a ser uma proeminente referência (DUIT, 2003) para a compreensão do processo de aprendizagem científica e de encaminhamento de propostas para o ensino de ciências. Surgido a partir do movimento das concepções alternativas nos fins dos anos setenta, o modelo de mudança conceitual constrói seus fundamentos baseados na filosofia da ciência (POSNER ET AL. 1982) e na psicologia cognitiva (OSBORNE; WITTROCK, 1983).

Com o avanço do modelo, duas estratégias principais de ensino são propostas de modo a haver a promoção da mudança conceitual (SCOTT et al., 1991, p. 312). Uma, de inspiração piagetiana, busca empregar conflitos cognitivos, com o objetivo de colocar em confronto as ideias prévias dos estudantes, opostas às científicas, para promover a mudança conceitual em direção ao conhecimento 
científico, esperando que o conhecimento prévio do aluno fosse abandonado. Em oposição a essa proposta, uma segunda estratégia faz uso de analogias e metáforas para desenvolver e estender as ideias prévias do aprendiz em direção ao ponto de vista científico, partindo de pontos comuns entre elas e, assim, evitando o confronto direto com as concepções do aluno. Apoiada na teoria de Ausubel (1978), tal estratégia estabelece que esquemas e conhecimentos previamente adquiridos pelo sujeito formem uma base de sustentação para tornar compreensíveis novos significados. A perspectiva ausubeliana estabelece que o conhecimento pré-existente do aprendiz oportuniza criar uma ponte conceitual entre os novos conceitos científicos a serem ensinados e as concepções que o estudante já possui. No processamento dos novos conceitos, consegue-se fundar um relacionamento não arbitrário e substantivo com as ideias prévias, por meio de um mecanismo cognitivo denominado ancoragem, que favorece uma aprendizagem significativa.

O ponto a destacar da segunda estratégia é o fato dela assumir que a mudança conceitual pode ser encorajada quando se provêem oportunidades aos estudantes para que construam um qualitativo e intuitivo entendimento do fenômeno, antes de haver o domínio dos seus princípios quantitativos. É a partir desse pressuposto que propomos a representação por desenhos, como estratégia de ensino para a aprendizagem de certos conteúdos de Física.

Entre os professores é senso comum que os alunos têm grandes dificuldades em aprender certas matérias, em particular a Física. Além de envolver um conjunto de informações e a construção de uma estrutura conceitual hierarquizada de conteúdos, como em geral acontece com outros conhecimentos, a natureza diferenciada da Física se sobressai em dificuldades adicionais, que são de ordem matemática. No caso do conhecimento físico existe uma relação indissociável entre abstrações conceituais e matemáticas, resultado de idealizações da natureza que, dentro do erro estatístico da medida, servem para operacionalização experimental e estabelecimento adaptativo (ARRUDA et al., 2001) entre a esfera empírica e as relações matemático-conceituais de esfera teórica. Acrescentadas a essas complicações, temos dificuldades relativas às destrezas no uso de equipamentos e técnicas de medição, a necessidade de considerações a respeito do conhecimento de fundo que forma a base empírica, além das crenças ontológicas e dos compromissos epistemológicos (CHINN; BREWER, 1993) que os alunos trazem para a sala de aula, reconhecidamente recalcitrantes à mudança. Todos esses pontos são obstáculos pedagógicos para a aprendizagem do conhecimento físico, podendo inexistir ou ser inexpressiva para outras matérias. 
Todavia, dentro do que nos interessa destacar, citemos a necessidade de simbolização que certos conteúdos de Física concentram. Por símbolos, não estamos a nos referir aos lógicos ou matemáticos, que pertencem ao domínio de dificuldade do conhecimento matemático já apontado, mas às representações convencionais, que envolvem um conhecimento mais de âmbito técnico. A título de ilustração, em óptica geométrica é possível ver representações de raios de luz ou lentes; em mecânica, três eixos ortogonais procuram significar o conceito de referencial; em ondulatória, frentes de ondas ou suas direções de propagação são utilizadas para idealizar ondulações mecânicas; no eletromagnetismo, linhas de campo são desenhadas com pontos e cruzes ou com traços retos ou curvos com pontas de flechas, isso sem mencionar as representações gráficas para tratar as funções matemáticas.

Diferente dos signos icônicos, que apresentam relação de similaridade ou analogia com o referente, os símbolos são signos adotados arbitrariamente, fundamentados numa convenção social, mantendo uma relação instituída, como as letras do alfabeto ou os algarismos (MEDEIROS; MEDEIROS, 2001; REGO, 1998). Os signos funcionam na memória como poderoso instrumento de mediação da linguagem e do pensamento, ampliando a nossa capacidade de ação sobre o mundo (OLIVEIRA, 1993). Na Física, os símbolos são convenientes elaborações para representar e tratar a realidade, simplificando o seu tratamento ${ }^{i}$. Servem de suporte para construção de entidades mentais ligadas a elementos diretamente perceptíveis, ou não, que os modelos incorporam. Assinalemos que certos símbolos físicos procuram guardar, por detrás da sua arbitrariedade figurativa, uma relação íntima, embora rudimentar, com a conceituação que pretendem significar. Essa característica de alguns símbolos auxilia não só a sua lembrança, mas principalmente a sua associação conceitual. É o caso do uso generalizado de flechas para comunicar grandezas Físicas conceitualmente distintas como força, velocidade, versores de sistemas de referência, linhas de campo, etc., e que têm por finalidade denotar abstratas grandezas vetoriais que, dependendo da concentração ou do comprimento das mesmas, sugerem intensidadesii; símbolos de capacitores procuram identificar objetos constituídos de seções separadas, podendo-se inferir que são uma barreira às correntes elétricas contínuas; o símbolo em ziguezague de resistores elétricos, em oposição aos fios de ligação, insinua a dificuldade para a corrente elétrica atravessar esses dispositivos, etc ${ }^{\text {iii }}$.

Ora, ainda que haja, num primeiro momento, dificuldades de memorização e de significação trazidas pelo afastamento da figuração simbólica da linguagem natural - circunstâncias estas de menor relevo para ícones, imagens ou fotos, 
mas que não estão igualmente desprovidos de problemas, conforme comentado no início do trabalho -, vimos que existem símbolos figurados de maneira não totalmente arbitrária que dão indícios em sua imagem do significado do conceito tratado. Caso isso acontecesse, caberia ao professor apontar e tornar tal significado consciente para o aprendiz. Embora se constate que não é costume esse recurso ser aproveitado durante as aulas, em princípio, é uma ação que, se considerada, vem a ser cognitivamente produtiva devido à associação conceitual engendrada e que acaba não terminando apenas em auxílio mnemônico de uma rápida recordação ou designação dos objetos representados. Fundamentalmente, essa ação torna-se promotora da aprendizagem do significado que está por detrás do símbolo especificado e da sua correspondente integração. Ao criar vínculos entre os conceitos do conteúdo trabalhado, a associação permite uma memorização ativa (OLIVEIRA, 1993, p. 26).

A Física é um conhecimento que faz uso de enorme quantidade de símbolos como marcas representativas para conceber, esquematizar e associar objetos, sistemas de dispositivos, formas ou fenômenos. Esses símbolos deveriam auxiliar tarefas com o objetivo de facilitar a memória, a própria conceituação, a atenção, a aplicação, a operacionalização e, por conseqüência, a resolução de problemas teóricos e práticos. Devido à relação de semelhança entre símbolo e referente ser afastada, deve-se ter em mente que adicionada à abstração envolvida com os conceitos de Física vem a exigência de memorização e do trato conceitual dos símbolos. A construção do significado e da figuração da codificação não é feita de maneira tão imediata como os professores costumam achar; não é só memorizar por simples associação o símbolo ao objeto ou ao conceito. Trabalhar com símbolos e seus esquemas envolve do aprendiz atividades cognitivas ligadas às atividades de tratamento e conversão (DUVAL, 2004, p. 42) , $^{\mathrm{iv}}$ além de um esforço extra de abstração e lembrança, que abrange, ainda, a necessidade da superação do caráter, em parte, assustador e de ansiedade que a aprendizagem da simbologia possui, pois o estudo perde o apoio no senso comum e se distancia do sentido concreto. Novamente, não estamos a considerar esses mesmos problemas envolvidos com a "matematização" dos conceitos físicos.

Agora, no que toca ao professor, a simples decoração, cópia ou memorização involuntária (MOREIRA, 1999) desses símbolos pelos alunos pode apontar um entendimento enganoso do assunto e ocultar falhas conceituais essenciais, que seriam importantes que fossem detectadas e explicitadas em determinados conteúdos, durante o processo de ensino. Consequentemente, os conteúdos que fazem uso 
de representações simbólicas deveriam estar na esfera de preocupação daquele que instrui.

Como costuma acontecer, as atividades de ensino que iniciam por convenções fazem com que os alunos cometam erros de codificação triviais e esquematização que mascaram incorreções de conceituação. São erroneamente interpretados pelos professores como simples inexatidão de memorização ou operacionalização dos símbolos. Da mesma forma como fizeram Colin \& Viennot (2002), quando se questiona os alunos sobre o que estão compreendendo a respeito de um esquema físico que desenharam de uma situação real, é possível aproveitar as falhas de figuração para discutir verdadeiros problemas de conceituação.

Assim, uma instrução que incorpore a linguagem baseada em desenhos à linguagem dos códigos oficiais da ciência e que permita um intercâmbio entre elas pode potencializar a revelação de dificuldades de aprendizagem, como a incompreensão do que está sendo representado e, por decorrência, dos conceitos teóricos envolvidos.

\section{Proposta do uso de desenhos}

Com o objetivo de minimizar os problemas levantados, propomos introduzir a linguagem de desenhos produzida pelo próprio aluno e utilizá-la em certos conteúdos de Física como estratégia de ensino. $\mathrm{O}$ desenho seria um mecanismo provisório de representação pessoal ou interpessoal, por isso, informal, intuitivo e evidente, para imaginar, de forma figurativa, objetos, fenômenos ou situações empíricas que estão começando a ser aprendidos. Seu objetivo é oportunizar que os estudantes iniciem o estudo de conteúdos carregados de simbologias de maneira qualitativa e espontânea, antes que haja uma preocupação obrigatória em estabelecer matematizações, quantificações e, principalmente, seus códigos e respectivas regras. Naturalmente, com a ausência no início da instrução dos códigos convencionados, as primeiras representações realizadas pelos alunos vão ser uma tentativa de cópia da situação observada, em função de não existir por parte deles nenhum comprometimento com convenções pré-estabelecidas. Assim, é espontânea a busca pelo aprendiz de uma semelhança quase fiel entre representado e representante. Devido ao desenho pessoal ou interpessoal elaborado ser uma imitação, a linguagem pictórica pode ser categorizada como linguagem baseada em signos de tipo icônicos.

Em termos pedagógicos, estamos sugerindo que o processo comunicativo em sala de aula se inicie por meio das representações pictóricas produzidas pelos 
estudantes, ao invés de começar pela apresentação de códigos, regras e definições, como normalmente se faz. Com isso, propicia-se a constituição de um ambiente de discussões, onde as primeiras reflexões conceituais sobre o assunto são travadas. Quanto à linguagem simbólica oficial, esta poderia ser introduzida passo a passo e em concomitância com a linguagem de desenhos, a fim de contrastá-las e elaborar associações entre elas e os conceitos envolvidos, iniciando, desse modo, o processo de conversão. Por esse encaminhamento, muitos obstáculos conceituais e de simbolização despontariam, podendo os mesmos ser discutidos e superados junto aos aprendizes nessas etapas, mas que, se deixados para serem debatidos junto a uma obrigatoriedade de uma prévia codificação, muito provavelmente, sofreriam dos problemas levantados. A articulação exclusiva da simbologia oficial seria exigida numa etapa a posteriori.

Em princípio, então, o uso de desenhos pretende ser um mediador que estimula e simplifica a aprendizagem, na medida em que não parte diretamente das simbologias convencionais e antiintuitivas que afastam o aluno, num primeiro contato com o assunto, de um entendimento mais satisfatório do que está sendo estudado. Ao mesmo tempo, seu uso torna-se um mecanismo de menor obstáculo para o surgimento de discussões de problemas e de incompreensões conceituais, que se mostram prejudicados quando atrelados às simbologias científicas. Com papel de representação intuitiva inicial, a representação por desenho é um instrumento de ensino que perscruta, com mais acuidade, o tipo de raciocínio que está sendo desenvolvido e construído, tornando-se uma alternativa adequada para indicar, rastrear e corrigir os problemas conceituais dos estudantes. Por último, a sua intermediação vem auxiliar, sem receios, a utilização dos símbolos convencionados, na medida em que estes já perdem o seu caráter intimidante de linguagem hermética, possibilitando agregar significados. O modo pictórico se coloca, portanto, como uma proposta para iniciar e acompanhar a instrução com a finalidade de abordar indiretamente a representação simbólica, tendo como preocupação o conteúdo associado a ela, por percepção bem mais mediada e substantiva do que quando se principia a instrução por códigos e regras.

É de se perceber que a linguagem através de desenhos permite-nos fazer uma aproximação com a segunda estratégia do modelo de mudança conceitual, mencionada no início da seção anterior. A aproximação se dá quando imaginamos um encaminhamento didático que estimule as intuições do estudante e a exploração dos seus conhecimentos, visando à facilitação e a apreensão de noções mais abstratas. 
Dentre os conteúdos de Física que utilizam símbolos, explorados no Ensino Médio, o de circuitos elétricos sobressai em quantidade. Nele, podemos constatar vários códigos e signos que são distantes das coisas que concebem. Para citar alguns, sejam os símbolos usados de capacitor, resistência elétrica, baterias, chaves conectoras, lâmpadas e fios elétricos. No caso destes últimos, eles são figurados como retas quase sempre simetricamente associadas, ligadas em noventa graus e convergindo num único ponto ou nó, dependendo da conveniência e simetria do esquema simbólico.

Tendo em vista que existe um vínculo solidário entre entender certos conceitos físicos que estão envolvidos no estudo de circuitos elétricos e operacionalizar sua esquematização simbólica de maneira correta e consciente, de modo que o aprendiz seja capaz de traduzir de maneira inteligível o que se acha subjacente à codificação produzida; e, considerando que simplesmente lembrar códigos, regras e fórmulas não significa demonstrar domínio conceitual do conteúdo; então, conseguir que o aprendiz ultrapasse a simples memorização ou cópia involuntária desses códigos e operacionalização mecânica é o objetivo para o qual toda instrução sempre se dedica.

Partindo disso, o objeto de nosso interesse volta-se à observação do alcance do emprego da linguagem pictórica na identificação das concepções dos alunos, quando em processo de ensino. Ou, mais especificamente, pretendemos verificar a potencialidade da estratégia pedagógica baseada no uso de desenhos dos alunos para expressar ou apontar dificuldades conceituais, quando do estudo de circuitos elétricos.

\section{Metodologia}

A natureza do tratamento de dados é qualitativa e se constitui de desenhos individuais produzidos pelos alunos, auxiliados por entrevistas vídeo-gravadas. Estas tiveram o objetivo de indicar e confirmar as concepções dos alunos que se encontravam implícitas nos desenhos, além de complementar informações da leitura da figura realizada pelo observador.

De uma amostra pesquisada, constituída de nove alunos, escolhida por conveniência entre vinte e seis estudantes de uma turma de terceiro ano do Ensino Médio, selecionamos cinco casos mais representativos e que melhor expressaram os pontos deste trabalho para discutir. Os estudantes pertenciam a uma escola pública do centro da cidade de Apucarana (PR). 
A retirada de dados deu-se em três momentos, denominados atividades de ensino. As atividades foram combinadas e discutidas com o professor da turma, que as inseriu durante a sua grade normal de aulas, respeitando a seqüência planejada do conteúdo por ele ministrado. Antes de iniciar uma atividade, os conteúdos pertinentes a cada uma delas foram desenvolvidos de forma tradicional. Tais condições permitiram deixar o professor à vontade, fazendo com que houvesse um mínimo de interferência da pesquisa na condução de suas aulas e na sua atuação na escola.

O domínio de discussão que se desejou atingir durante as atividades de ensino junto aos alunos teve a intenção de ficar limitado a questões de esquematização e conceitos correlatos, priorizando-se o raciocínio qualitativo e intuitivo, em detrimento da apresentação dos códigos oficiais e formalismos matemáticos. Excluindo a terceira atividade, os alunos reunidos em grupos puderam montar diferentes circuitos elétricos relativos a cada atividade, sendo-lhes possível investigar de maneira livre os seus funcionamentos. Por detrás da elaboração das atividades houve a preocupação de explorar as dificuldades conceituais dos alunos no assunto $\mathrm{e}$, para isso, foram aproveitados os resultados de diversas pesquisas sobre o tema (PACCA et al., 2003; SAXENA, 1992; SHIPSTONE et al., 1988; SOLOMON et al., 1985). Precedendo a primeira atividade de ensino, o professor trabalhou os conteúdos de corrente elétrica, resistência e diferença de potencial. Entre a primeira e a segunda atividades, foram estudadas as características das associações série e paralelo. Os conceitos previamente estudados foram aplicados na primeira atividade de ensino, que durou duas aulas. A atividade consistiu na construção e discussão de um circuito elétrico em que se conectava em série uma lâmpada de piscapisca de Natal a uma chave interruptora e a uma bateria. Na aula seguinte, solicitou-se que os alunos desenhassem um circuito elétrico simples, capaz de acender uma lâmpada. Além de especificar as ligações, os alunos deveriam representar por meio de setas o sentido da corrente elétrica. O objetivo desta atividade foi observar como os estudantes estavam entendendo os conceitos desenvolvidos de circuito fechado ou aberto, e que modelo de corrente apresentavam.

Na segunda atividade, com duração também de duas aulas, os alunos verificaram o que acontecia com o brilho de uma lâmpada, quando se adicionava uma segunda e uma terceira lâmpada idênticas em série. Ao pedido do professor, os aprendizes fizeram duas modificações no circuito, alterando a ordem das lâmpadas e as ligações dos pólos da bateria. A finalidade dessas ações era constatar que a intensidade da corrente elétrica não dependia do sentido convencional adotado da corrente elétrica e nem da ordem dos elementos no circuito, como é comum os 
aprendizes pensarem, conforme alerta McDermott (2006). Na aula seguinte, foi solicitado aos alunos que desenhassem um circuito elétrico com três lâmpadas idênticas em série, com bateria e chave interruptora. Com isso, tinha-se o objetivo de verificar as possíveis dificuldades que haviam permanecido quanto às características de uma associação desse tipo.

A terceira atividade teve como objetivo romper com a padronização das disposições figurativas simétricas, comumente usadas nos livros e por professores, motivadas fundamentalmente por uma preocupação com a facilitação gráfica das associações dos dispositivos e com a estimulação de uma harmonia estética, provocada pela simplicidade dada pela regularidade visual. Nesta atividade, os alunos deviam traçar associações em série e em paralelo em dois conjuntos de dispositivos elétricos, constituídos de um par de lâmpadas e bateria, espacialmente dispostos como na Fig. 1. A figura exibe os dispositivos alinhados de modo a alterar as simetrias habitualmente vistas no estudo dessas ligações. A justificativa para estudar esse tipo de situação surge da constatação de Prain \& Waldrip (2006, p. 1856), também percebida por Duit e von Rhönec (1997), de que variações relativamente pequenas que disfarcem a organização das representações interferem na capacidade dos estudantes em construir circuitos, sugerindo um não entendimento dos conceitos. Para Duval (2004), constituem-se verdadeiros obstáculos à apreensão operatória das figuras quando se as reorganiza perceptivelmente. Os obstáculos dependem do grau de complexidade do tratamento Fig. 1 produzido, via aumento, diminuição, deslocamento por rotação ou translação, etc., no momento em que se impõe uma operação de "reconfiguração" ao se reorganizar ou variar um desenho de um tipo a outro equivalente (ibid., p. 165, 173). Assim, na necessidade do sujeito em explorar todas as variações figurais possíveis, pode-se identificar o alcance da validez de um raciocínio. Para isso, observou-se o preenchimento da Fig. 1 pelo aprendiz, notando se ele realizava as conexões em série e paralelo independentemente da disposição geométrica, de tal modo que aplicasse os conceitos estudados. Por conseguinte, essa atividade possibilitou constatar se a semiótica visual usada não foi exclusivamente fruto de uma aprendizagem literal, baseada em condicionamentos ou mesmo produto de uma linguagem vulgar de ordenamento seqüencial, isto é, se as palavras série e paralelo não terminavam querendo dizer estar em fila e lado a lado, respectivamente, sem significar o conceito desejado. 


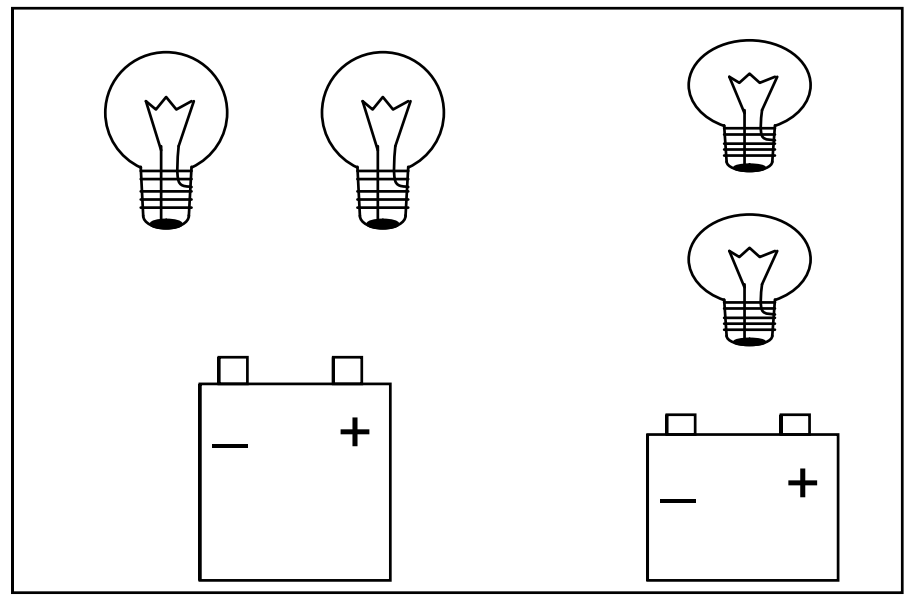

Fig. 1 - Dois conjuntos com par de lâmpadas e bateria para serem ligados em série e depois em paralelo.

\section{Apresentação e análise de dados}

Vamos verificar agora que as dúvidas e os erros explicitados pelos alunos por meio dos desenhos foram de elaboração de esquematização e concomitante conceituação, assemelhando-se, neste caso, às conhecidas concepções alternativas mantidas pelos alunos sobre o assunto (cf., p.ex., SAXENA, 1992; SHIPSTONE et al., 1988; SOLOMON et al., 1985).

$\mathrm{Na}$ análise das figuras, usamos as falas dos alunos para descrever as falhas de representação e raciocínio. Essas falas, assim como as do professor, se encontram entre aspas e em itálico. Entre parênteses, são inseridas as notas do observador, com a finalidade de esclarecimento. Cada aluno está exemplificado em uma única atividade.

Pela Fig. 2, identificamos um conjunto de erros de representações na atividade 1, indicando os problemas conceituais da aluna Camila. O primeiro erro de representação refere-se à quantidade de fios ligados à pilha. Conforme se vê, nos pólos deste dispositivo conectam-se quatro fios (A, B, C e D), interligados nos pontos 1 e 2 . O segundo problema é notado nos curtos-circuitos (pontos 1 e 2). Os erros indicam a concepção de Camila sobre corrente elétrica. Ela coloca a seta indicativa a partir do ponto 1, onde "as cargas se juntam" (somam-se as cargas positivas e negativas dos fios $\mathrm{C}$ e A que saem da bateria). Após a chave, no ponto 
Caso 1: Aluna Camila (Atividade 1)

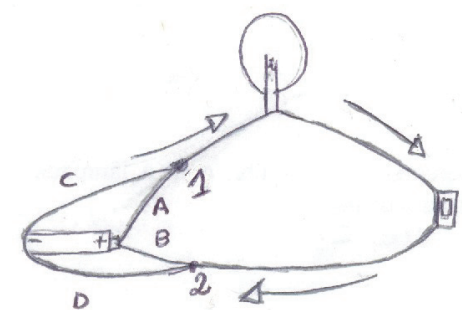

Fig. 2 - Desenho da atividade 1 da aluna Camila.

2, as cargas "voltam para os seus pólos", e reinicia-se o processo até o momento em que "acaba a energia da pilha". A concepção de que a corrente elétrica é formada pela junção das cargas positivas e negativas é vista pela necessidade da estudante ao colocar os curtos-circuitos 1 e 2 . Ao ser indagada sobre a diferença de potencial entre os pontos 1 e 2 , afirma ser de $1,5 \mathrm{~V}$, o que é uma demonstração clara de que ela não entendeu o conceito de diferença de potencial, e/ou não entende o que é um fio condutor e, consequentemente, não entende que os pontos 1 e 2 , apesar de figurativamente deslocados, estão sob o mesmo potencial.

Outra concepção presente é da pilha como fonte de corrente, como mostra a fala: "a corrente que sai da pilha vai passando pelos fios, chega até a lâmpada que está ligada a uma chave e retorna para a pilha, e aí completa o circuito". A fala indica um raciocínio seqüencial em que a corrente elétrica passa por cada elemento do circuito um a um, percorrendo todo o circuito, que irá funcionar "até acabar a energia da pilha”. Como é comentado em Santos (1991, p. 104), Camila "substancializa ideias abstratas" ao considerar a eletricidade como algo material que parte de uma fonte e que atravessa, sequencialmente, os diferentes elementos de um circuito.

O desenho de Camila indica dificuldades conceituais, todavia, revela não haver nenhum ponto aberto, o que é influência do ensino da noção de circuito fechado, indicada pelas setas que fornecem o sentido da corrente.

Na Fig. 3, constatamos a chave colocada em paralelo com a lâmpada e a bateria, indicando uma severa incompreensão. Flaviane, imaginando que seu circuito estava correto, já que essa configuração "funciona" segundo suas expectativas, não percebe que, ao ligar a chave, é bem sucedida na sua ação de desligar a lâmpada mas, de fato, acaba colocando em curto-circuito a bateria, descarregando- 
Caso 2: Aluna Flaviane (Atividade 1)

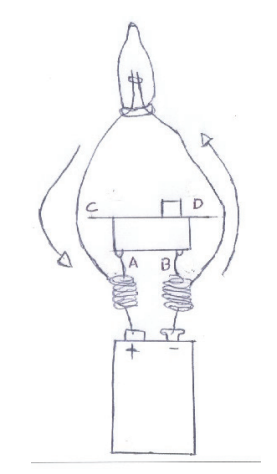

Fig. 3 - Desenho da atividade 1 da aluna Flaviane. As molas representadas são conectores usados para ligar os fios e dispositivos elétricos.

a. Contrariamente, quando desliga a chave, pensando que a está ligando, a lâmpada acende, dando a impressão de que o circuito por ela montado está correto. Agora, o que se infere da representação é o não entendimento do funcionamento da chave conectora pois, após ser alertada da inversão da mesma e ao ser questionada sobre o que acontece quando se liga a chave (que para ela era uma ação de desligar), Flaviane afirma: "A lâmpada apaga... porque ela (a chave) deve estar dificultando a passagem de corrente". Para a aluna, a chave se comporta como se fosse um resistor. Isso é confirmado no momento em que ela, ao ser questionada sobre o valor da resistência da chave ligada, diz que "não sabe", apesar de mostrar que conhece o que é resistor ("É (...) oferecer resistência à passagem de corrente."). Portanto, pela figura e entrevista, conclui-se que a chave conectora não deveria ser considerada um elemento trivial para a compreensão de circuitos elétricos, como se costuma imaginar, levado pela simplicidade de seu funcionamento, ou seja, de simples interruptor, ou não, de corrente elétrica. Certamente, o caso da aluna Flaviane é um exemplo didaticamente importante a ser considerado em sala de aula, na medida em que possibilita acusar incompreensões semelhantes à descrita.

$\mathrm{Na}$ representação de Roney (Fig. 4), percebe-se que ligação em série significa apenas ordenação seqüencial dos dispositivos, pois manifesta pelos curtoscircuitos que não tem compreensão do que é um circuito elétrico e nem, consequentemente, de diferença de potencial. Pela figura é possível inferir que um problema central gerador dessas dificuldades se localiza, sem considerar a bateria, na 
Caso 3: Aluno Roney (Atividade 2)

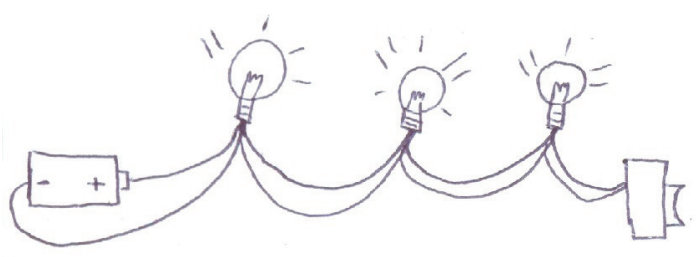

Fig. 4 - Desenho da atividade 2 do aluno Roney.

incompreensão de que os dispositivos em foco têm dupla conexão para o seu funcionamento. A existência dessa noção exclusiva à bateria talvez se deva ao destaque de seus pólos nesse componente elétrico, como ele mesmo mostra. Ainda pelo desenho, constata-se que as lâmpadas estão acesas (linhas representando luz sobre elas), com somente um terminal conectado. Isso é evidência de um obscuro modelo de corrente elétrica através das lâmpadas. Esse tipo de raciocínio é produto de uma concepção comum, reforçada pela interação das pessoas com o entorno tecnológico. O diário procedimento de manipulação de uma lâmpada caseira, aliado à falta de conhecimento científico sobre corrente elétrica, acaba por reforçar ou induzir à concepção de que lâmpadas só precisam de uma conexão para funcionar. Como mostram Engelhardt \& Beichner (2004), um terço dos sujeitos por eles pesquisados acreditavam que nas lâmpadas só há necessidade de uma conexão, localizada no fundo da lâmpada para acioná-la. Freqüentemente, nos dispositivos elétricos a que temos acesso diretamente, o par de fios de suas conexões não está saliente, por questão de facilidade operacional e de segurança. Quando se está desprovido de uma referência teórica correta, se é facilmente conduzido a pensar que as lâmpadas e outros componentes elétricos podem funcionar apenas com uma conexão ou um terminal. Torna-se natural, portanto, que as ações cotidianas com lâmpadas ou outras conexões conduzam ao entendimento de que a passagem da corrente elétrica se dê por um único fio condutor e que isso seja suficiente para o funcionamento dos dispositivos elétricos.

Embora os sujeitos saibam, por experiências mal sucedidas, também do dia-a-dia, que encostar dois fios da instalação elétrica provoca um "estouro" ou "curto", no caso, o aluno Roney não foi capaz de transferir esse conhecimento para a sala de aula, como demonstra seu desenho. Entretanto, ao ser provocado a refletir sobre isso, ele inicia uma tomada de consciência do seu equívoco, como observamos pelo trecho da entrevista: (Professor) "Agora, voltando ao seu desenho. Você 
liga os dois fios num só ponto e, deste, leva outros dois fios para a segunda lâmpada e para a terceira até chegar à chave. Agora, pense na seguinte situação: na sua casa, se você pegar dois fios e encostar um no outro, o que acontece?" (Roney) "Estoura. Dá curto... Entendi. Coloquei as três lâmpadas em curto". (Professor) "Todas as lâmpadas vão acender? (Roney) "Não, nenhuma".

Caso 4: Aluno Gabriel (Atividade 2)

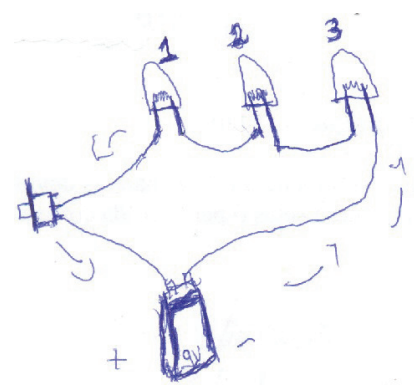

Fig. 5 - Desenho da atividade 2 do aluno Gabriel.

O desenho de Gabriel representa corretamente a associação em série, o que indica a aprendizagem da maneira como devem estar ligados os elementos de um circuito elétrico e a necessidade de ser fechado, indicado pelas setas representando a corrente elétrica. Porém, revela a persistência do modelo de atenuação da corrente elétrica ao longo do circuito, ao afirmar que "a lâmpada três recebe maior corrente, a dois fica com menos e a lâmpada um com o restante, menos que a dois". A falta de indicação da corrente elétrica entre as lâmpadas na figura 5 chama a atenção. Contudo, pela fala avalia-se isso como uma simples desconsideração do aluno, sem maior relevância, uma vez que há continuidade na corrente em todo o desenho.

O caso do desenho de Gabriel é de relevância ao permitir advertir que o emprego pedagógico exclusivo da semiótica pictórica para extrair, identificar e acompanhar os significados científicos ensinados é limitado. Se não fosse pelo expediente semiótico oral, permitido pela entrevista, o problema conceitual do desgaste da corrente ao longo do circuito passaria despercebido, assim como a falta de representação da corrente entre as lâmpadas poderia ser interpretada como inexistência desta. Isso demonstra que, junto ao recurso do desenho, alternativas semióticas auxiliares complementam a análise do que os sujeitos estão pensando e que qualquer tipo de representação não é auto-suficiente. 
Caso 5: Aluna Graziele (Atividade 3)
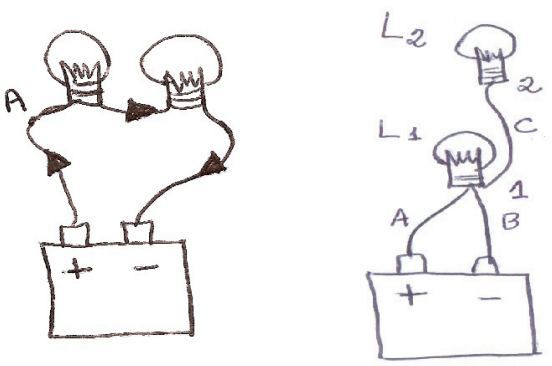

Fig. 6 - Atividade 3 da aluna Graziele: associação em série.

Com base na atividade 3, a Fig. 6 mostra o desenho de Graziele ao tentar associar as duas lâmpadas em série à bateria, em duas disposições espaciais. No lado esquerdo da figura, em que as lâmpadas estão dispostas horizontalmente, a estudante "corretamente" desenha o circuito, indicando, também acertadamente, a corrente elétrica ao longo do caminho. Com as aspas, queremos fazer perceber que os fios de ligação estão nas laterais dos soquetes das lâmpadas, dando a impressão de se acharem em curto-circuito. Mas, pela entrevista, constatou-se que a aluna queria, de fato, mostrar que cada fio ligava-se ao filamento dentro da lâmpada e que a corrente passava através do mesmo: “... de um fio você liga desse ponto (mostrando o ponto A) e vai passando até chegar na última lâmpada" (Segue percorrendo manualmente com a lapiseira os fios em série do lado esquerdo da Fig. 6, passando pelos filamentos das lâmpadas de modo coerente, para mostrar o que ela estava pensando). O filamento é tratado por ela de forma equivalente aos resistores - inclusive, com o mesmo símbolo -, conforme fora ensinado antes dessa atividade. Assim, para Graziele, as linhas laterais do desenho dos soquetes são extensões dos terminais dos filamentos, semelhantes ao desenho da lâmpada de Natal mostrada na Fig. 5. Agora, é perceptível que a aluna não realiza corretamente a mesma associação no lado direito da figura. Há aí uma ausência de compreensão do conceito de circuito fechado e, por conseguinte, de corrente elétrica. A lâmpada 2 do lado direito da Fig. 6 está com apenas um dos seus terminais ligados, deixando o circuito aberto nesse ponto. Dessa forma, não existe um percurso condutor fechado entre os terminais da pilha por esta lâmpada. Igualmente, vê-se que a bateria está posta em curto-circuito no pino do terminal do soquete da lâmpada 1.

Apesar de Graziele responder satisfatoriamente à indagação do que entende por ligação em série e ter corretamente representado a representação horizontal, 
isso não é garantia de que tenha estruturado o significado desse tipo de associação, assim como do conceito de corrente e de circuito fechado, já que as mesmas regras aplicadas na disposição horizontal não são transferíveis para a vertical.

O seu desenho na Fig. 7, de ligação em paralelo, segue o mesmo padrão da figura antecedente. No lado esquerdo da Fig. 7 observa-se o desenho correto. Aí, semelhante ao caso esquerdo da Fig. 6, a aluna realiza as ligações sobre as lâmpadas como se fossem os resistores ensinados antes da atividade; as laterais dos soquetes das lâmpadas são novamente usadas como extensão dos terminais dos filamentos. Todavia, ao realizar a mesma associação no lado direito da Fig. 7 acaba fazendo uma ligação em série e, como se pode ver, representa corretamente as ligações nos terminais dos soquetes das lâmpadas. $\mathrm{O}$ cruzamento dos fios no ponto A dessa mesma figura não é um curto-circuito, mas um fio passando por cima do outro, como mostra a entrevista: (Professor) "Observe, vou colocar um ponto A no seu desenho. Esses fios neste ponto A estão ligados?" (Graziele) "Não". (Professor) "Então, explique-me como você fez essa ligação?" (Graziele) "Ah, fiz assim. Liguei o fio do positivo da bateria até a lâmpada dois, depois liguei com a lâmpada um, cruzei (passou por cima) e liguei no negativo".
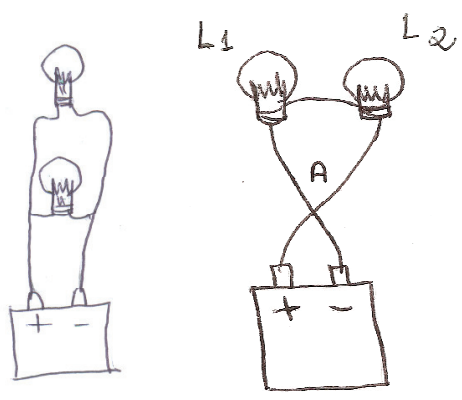

Fig. 7 - Atividade 3 da aluna Graziele: associação em paralelo.

À primeira vista, as associações desenhadas nos lados esquerdos das Fig. 6 e 7 de Graziele estão corretas, parecendo que ela entendeu as respectivas associações. Porém, de fato, Graziele faz uma cópia literal, em vez de uma compreensão não-arbitrária e substantiva (MOREIRA, 1999) do que foi estudado. Uma primeira demonstração disso é a questão mencionada das ligações nas laterais dos soquetes das lâmpadas. Essa forma de representação é justamente a ministrada em sala, em que o professor usou os códigos oficiais de resistores. A segunda demonstração é vista quando se faz necessário realizar uma mesma associação em uma nova confi- 
guração, ou, mais precisamente, quando a estudante precisa realizar uma operação de reconfiguração. No lado direito da Fig. 7, a estudante realiza uma ligação em série, em vez da solicitada ligação em paralelo e, também, do mesmo lado da Fig. 6 , reaparecem graves dificuldades conceituais de corrente elétrica, expostas nos curtos-circuitos e na ligação em aberto da lâmpada $\mathrm{L}_{2}$. Desse modo, a variação do arranjo espacial torna-se conflituosa para a estudante e reforça sua falta de entendimento dos conceitos.

Veja-se que, pelas ligações representadas nos soquetes das lâmpadas do lado esquerdo das Fig. 6 e 7, poder-se-ia supor que é obscura a estrutura interna da construção das lâmpadas para Graziele, como se afirmou para o caso da chave interruptora de Roney na Fig. 4. Só que, pelas figuras do lado direito de Graziele, com destaque dado para a segunda, tal suposição não é correta. Há, sim, um maior nível de dificuldade encontrado por Graziele ao realizar ligações em série e paralelo quando os dispositivos não se encontram visualmente apresentados nas seqüências espaciais trabalhadas em classe, o que faz transparecer uma aprendizagem mais mecânica, ligada à simples reprodução do que foi ensinado, do que uma aprendizagem significativa.

\section{Conclusão}

Normalmente, as simbologias oficiais e suas regras são consideradas periféricas no processo de entendimento conceitual e, por isso, têm merecido pouca atenção nas discussões na educação científica. Todavia, elas são elementos de empecilho na trajetória de construção conceitual do aprendiz, e é nesse ponto de vista que o estudo aqui desenvolvido procurou se situar.

O trabalho tentou destacar que o uso de desenhos é um instrumento didático produtivo para ser utilizado em sala de aula no estudo de circuitos elétricos. Essa forma de representação permite ser um indicativo ágil e eficaz das falhas conceituais dos aprendizes, podendo ser aproveitado para redirecionar as ações durante o processo de ensino. É possível concluir que, durante a iniciação da elaboração dos conceitos físicos, em circuitos elétricos, não há muito sentido em ficar exigindo dos alunos os abstratos códigos oficiais, porquanto vimos que, ao realizarem suas representações, eles apresentam um conjunto de dificuldades conceituais e podem até mesmo não compreender o funcionamento ou a operação de certos dispositivos elétricos. Dentro de uma atividade de ensino, principalmente como a do conteúdo aqui em foco, seria mais sensato que a articulação das simbologias convencionais fosse deixada para o fim de uma etapa de instrução, ao invés de ser 
exigência logo na introdução do assunto, como é costume acontecer. A linguagem abstrata dos símbolos oficiais, ao ser usada para facilitar as operações e os raciocínios envolvidos com o conteúdo, acaba por esconder do professor as dificuldades dos seus alunos, que costumam trabalhar com elas de forma mecânica, sem realmente entendê-las.

Mas, o caso do estudante Gabriel é um exemplo indicativo de que a estratégia por meio do desenho tem seus limites. Como se viu, apesar de seu desenho se encontrar certo, ele apresenta conceitos e noções incorretas. Inversamente, um desenho pode sugerir a existência de incorreções sem que realmente elas existam, como é o caso de Graziele discutido. Enfim, a representação por desenho não é auto-suficiente e não prescinde de outras formas de representação, como a verbalização, por exemplo.

Fica, assim, a sugestão do emprego da modalidade instrucional baseada nos desenhos dos alunos, para o professor ir acompanhando a construção do conhecimento de seus estudantes. A estratégia por desenho, ao antecipar a utilização de codificações, esquemas e regras oficiais a serem ensinadas, serve de mediação para estimular reflexões e discussões junto aos alunos, com a finalidade de favorecer um apropriado ambiente intelectual para superar os problemas conceituais dos educandos.

\section{Agradecimentos}

Estamos gratos às sugestões dos pareceristas anônimos.

\section{Bibliografia}

ARRUDA, S. M.; SILVA, M. R.; LABURÚ, C. E. Laboratório didático de Física a partir de uma perspectiva kuhniana. Investigações em Ensino de Ciências, v. 6, n. 1, p. 1-9, 2001.

AUSUBEL, D. P. Psicología educativa: un punto de vista cognoscitiva. México: Trilhas, 1978.

CHINN, C. A.; BREWER, W. F. The role of anomalous data in knowledge acquisition: a theoretical framework and implications for science instruction. Review of Educational Research, v. 63, n. 1, p. 1-49, 1993. 
COHEN, R.; EYLON, B.; GANIEL, U. Potencial difference and current in simple electric circuits: a study of students' concepts. American Journal of Physics, v. 51, n. 5, p. 407-412, may 1983.

COLIN, P.; VIENNOT, L. Reading images in optics: students' difficulties and teachers' views. International Journal of Science Education, v. 24, n. 3, p. 313332,2002

DUIT, R. Conceptual change: a powerful framework for improving science teaching and learning. International Journal of Science Education, v. 25, n. 6, p. 671-688, 2003.

DUIT, R.; VON RHÖNEC, C. Learning and understanding key concepts of electricity. Disponível em:

$<$ http:www.physics.ohiostate.edu/ jossen/ICPE/c2html.1997> Acesso em: 14 mai. 2006.

DUVAL, R. Semiosis y pensamiento humano: registros semióticos y aprendizajes intelectuales. Santiago de Cali, Colombia: Universidad del Vale, Instituto de Educación y Pedagogía, 2004.

DUVAL, R. A cognitive analysis of problems of comprehension in a learning of mathematics. Educational Studies in Mathematics, v. 61, p. 103-131, 2006.

ENGELHARDT, P. V.; BEICHNER, R. J. Students' understanding of direct current resistive electrical circuits. American Journal of Physics, v. 72, n. 1, jan. 2004.

McDERMOTT, L. Comments on c2: learning and understanding key concepts in electricity. Disponível em:

$<$ http://www.physics.ohio-state.edu/ jossem/ICPE/C2Mc.html $>$ Acesso em: 15 mai. 2006

MEDEIROS, A.; MEDEIROS, C. Questões epistemológicas nas iconicidades de representações visuais em livros didáticos de Física. Revista Brasileira de Pesquisa em Educação em Ciências, v. 1, n. 1, p. 103-117, 2001.

MOREIRA, M. A. Aprendizagem significativa. Brasília: Editora Universidade de Brasília, 1999. 
OLIVEIRA, M. K. Vygotsky, aprendizado e desenvolvimento. Um processo sócio-histórico. Série Pensamento e Ação no Magistério. São Paulo: Editora Scipione, 1993.

OSBORNE, R. J.; WITTROCK, M. C. Learning science: a generative process. Science Education, v. 67, n. 4, p. 489-508, 1983.

PACCA, J. L. A. et al. Corrente elétrica e circuito elétrico: algumas concepções do senso comum. Caderno Brasileiro de Ensino de Física, v. 20, n. 2, p. 151-167, 2003.

PINTÓ, R.; AMETLLER, J. Students' difficulties in readings images. Comparing results from four national research groups. International Journal of Science Education, v. 24, n. 3, p. 333-341, 2002.

POSNER, G. J.; STRIKE, K. A.; HEWSON, P. W.; GERTZOG, W. A. Accommodation of scientific conception: Toward a theory of conceptual change. Science Education, v. 66, n. 2, p. 221-227, 1982.

PRAIN, V.; WALDRIP, B. An exploratory study of teachers' and students' use of multi-modal representations of concepts in primary science. International Journal of Science Education, v. 28, n. 15, p. 1843-1866, 2006.

REGO, T. C. Vygotsky: uma perspectiva histórico-cultural da Educação. 6. ed. Editora Vozes, 1998.

SANTOS, M. E. Mudança conceptual na sala de aula: um desafio pedagógico. Lisboa: Livros Horizonte, 1991.

SAXENA, A. B. An attempt to remove misconceptions related to electricity. International Journal of Science Education, v. 14, n. 2, p. 157-162, 1992.

SCOTT, R.; ASOKO, H. M.; DRIVER, R. Teaching for conceptual change: a review of strategies. In: DUIT, R. et al.(Eds.) INTERNATIONAL WORKSHOP, 1991, University of Bremem. Proceeding... p. 310-329.

SILVEIRA, F. L. ET AL. Validação de um teste para verificar se o aluno possui concepções científicas sobre corrente elétrica em circuitos simples. Ciência e Cultura, v. 41, n. 11, 1989, p. 1129-1133.

SHIPSTONE, D. M.; von RHÖNECK, C.; JUNG, W.; KÄRRQVIST, C.; DUPIN, J, J.; JOSHUA, S.; LICHT, P. A study of students' understanding of electricity in 
five European countries. International Journal of Science Education, v. 10, p. 303-316, 1988.

SOLOMON, J.; BLACK, P.; OLDHAM, V.; STUART, H. The pupils' view of electricity. European Journal of Science Education, v. 7, n. 3, p. 281-294, 1985.

STYLIANIDOU, F.; ORMEROD, F.; OGBORN, J. Analysis of science textbook pictures about energy and pupils' readings of them. International Journal of Science Education, v. 24, n. 3, p. 257-283, 2002.

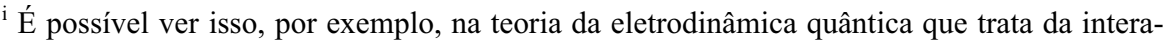
ção da radiação com a matéria e que unificou a eletrodinâmica clássica com a mecânica quântica. Quando se comparam as ideias de Feynman com as de Schwinger e Tomonaga a respeito da eletrodinâmica quântica, que abordam o mesmo conjunto de ideias, mas sob pontos de vista diferentes, Dyson, em 1948, demonstrou que a simplificação dos cálculos da teoria de Feynman, em relação ao tratamento dos outros dois autores, em grande parte deveu-se à introdução dos seus diagramas. Feynman emprega um método muito mais simples do que a longa série de cálculos formais de Schwinger baseado em uma representação visual dos seus gráficos ou diagramas (CASTELLANI; CASTELLANI, 2005, p. 62a).

ii Devemos mencionar que as mesmas flechas são usadas como esquemas nos textos com os mais variados e distintos propósitos: para apontar explicações, sinalizar distâncias, dar a noção de deslocamento de algo como o imponderável fluxo de calor num esquema de máquina térmica, corrente elétrica num circuito, deslocamento de um feixe de luz ou, simplesmente, o rumo de um móvel.

iii No caso específico das figuras de flechas, vemos o quanto é simplificada e apropriada essa maneira de representar quando se imagina substituir o sinal reto das flechas $(\rightarrow)$ por um sinal, por exemplo, semicircular ou tortuoso com dois pontos em cima (ق) para comunicar que há uma força aplicada em um móvel. Certamente, as últimas convenções impingem um inconveniente afastamento da intuição do que está sendo representado e uma desnecessária complicação para desenhar, como é o caso de quando se utiliza o símbolo de um retângulo para resistores elétricos em vez do tradicional ziguezague. É de se atentar, também, para o emprego de diversos tipos de símbolos nos aparelhos eletrônicos. Eles procuram sinalizar variados aspectos como volume, ligado/desligado, velocidade, direção (p.ex. em certos vídeos temos um e dois triângulos deitados se contrapondo, querendo dizer "play" (tocar) e avanço rápido, respectivamente), gravação (dois círculos separados por uma reta que os tangenciam, tentando denotar um antigo sistema de gravação magnética), etc.
\end{abstract}

iv As atividades de tratamento e conversão são propriedades de transformação ligadas aos registros de representação (DUVAL, 2006, p. 111). A primeira se dá no interior do próprio registro e não mobiliza mais do que um registro. A segunda envolve mudança de registro, sendo que cada registro mantém suas regras distintas de tratamento (DUVAL, 2004). 